\title{
INTRATHECAL PRESERVATIVE-FREE KETAMINE WITH BUPIVACAINE IN COMPARISON WITH BUPIVACAINE ALONE FOR LOWER LIMB AND LOWER ABDOMINAL SURGERIES- A CLINICAL STUDY
}

\author{
Sreekumar $V^{1}$, Veena $N^{2}$
}

${ }^{1}$ Consultant Anaesthesiologist, Department of Anaesthesiology, Taluk Hospital, Cherthala, Alappuzha, Kerala. ${ }^{2}$ Associate Professor, Department of Anaesthesiology, Government T. D. Medical College, Alappuzha, Kerala.

\section{ABSTRACT}

\section{BACKGROUND}

Pain relief is a basic human right and failure to relieve pain is morally and ethically unacceptable. The concept of postoperative pain relief and its utilisation has improved dramatically over recent years. In the present study intrathecal administration of ketamine is evaluated with respect to its anaesthetic properties, intraoperative and post-operative haemodynamic profile and duration of analgesia.

\section{MATERIALS AND METHODS}

60 ASA Grade 1 and 2 patients undergoing lower limb and lower abdominal surgery under spinal anaesthesia were included in two groups of thirty each to receive intrathecal bupivacaine with ketamine and intrathecal bupivacaine alone. Onset of sensory blockade up to $\mathrm{T}_{10}$ level, intraoperative and postoperative vital signs, duration of analgesia and side effects, if any were evaluated.

\section{RESULTS}

It was found that the onset of sensory block in the Bupivacaine only group was $129.67 \mathrm{sec}$ (Mean), while in the Bupivacaine plus Ketamine group it was $92.5 \mathrm{sec}$ (Mean) and this was statistically significant $(\mathrm{P}=0.000)$. Fall in mean arterial pressure in the Bupivacaine only group was $23.63 \%$ (Mean), while in the Bupivacaine plus Ketamine group was $14.53 \%$ (Mean). This was statistically significant $(\mathrm{P}=0.000)$. Incidence of bradycardia was statistically lower in the Bupivacaine plus Ketamine group. There is no statistically significant difference in the duration of analgesia in both the groups. Side effects like nausea, vomiting, sedation and nystagmus were more with the Bupivacaine plus Ketamine group. Shivering was noted in 10 patients in the Bupivacaine group, while none of the patients in the Bupivacaine plus Ketamine group had so.

\section{CONCLUSION}

Preservative-free ketamine can be added to Bupivacaine 0.5\% (Heavy) for spinal anaesthesia in lower abdominal and lower limb surgeries, which would produce optimal operating conditions with a faster onset of sensory blockade and a better haemodynamic profile. The mild sedation and the local anaesthetic sparing effects can be beneficial.

\section{KEYWORDS}

Lower Abdominal and Lower Limb Surgeries, Spinal Anaesthesia, Intrathecal Ketamine, Intraop Vital Signs Stability.

HOW TO CITE THIS ARTICLE: Sreekumar V, Veena N. Intrathecal preservative-free ketamine with bupivacaine in comparison with bupivacaine alone for lower limb and lower abdominal surgeries- a clinical study. J. Evolution Med. Dent. Sci. 2017;6(42): 3309-3312, DOI: $10.14260 / \mathrm{Jemds} / 2017 / 716$

\section{BACKGROUND}

Spinal anaesthesia is popular for lower abdominal and lower limb surgeries, because of its unique advantages over general anaesthesia. The distinct advantages of spinal anaesthesia over general anaesthesia are minimum physiological disturbance resulting in minimum stress response, optimal operative conditions, minimal intraoperative blood loss and less chance of post-operative morbidity.

Various local anaesthetics have been used to produce subarachnoid block, of which popularly used one is Bupivacaine hydrochloride $0.5 \%$ (Heavy). Additives can be added along with the local anaesthetics to get favourable responses such as reduction of systemic toxicity of local anaesthetics, prolongation of duration of action of local

Financial or Other, Competing Interest: None.

Submission 30-03-2017, Peer Review 12-05-2017,

Acceptance 19-05-2017, Published 25-05-2017.

Corresponding Author:

Dr. Veena $N$,

Kovilakam, Pazhaveedu P. O.,

Alappuzha, Kerala.

E-mail: drveenadutt@gmail.com

DOI: $10.14260 /$ jemds $/ 2017 / 716$ anaesthetics, increasing the potency of block and thereby the reliability of the block, etc. Ketamine is one among them. Kitahata, Taub, Kosaka(1) have suggested that the analgesic action of Ketamine can be explained by lamina specific suppression of spinal cord activity. Stereospecificity of Ketamine in binding to opiate receptors has been demonstrated. (Phencyclidine sensitive sigma 1 receptors) by Smith DJ, Westfall et al(2) in 1980 and Finck, Nagi in 1982. The major sites of Ketamine analgesia have been demonstrated as periaqueductal grey matter, nucleus raphe magnus and spinal cord dorsal horn and pain pathways involving endogenous opiate and 5-HT neurotransmission.

A contribution by central noradrenaline inhibition is also considered (GM Pekoe, DJ Smith, 1980(3)). Proposed mechanisms of action of Ketamine as a Spinal Anaesthetic-

1. Ketamine may bind to opiate receptor as an agonist. $4,5,6$

2. Ketamine may act as an NMDA antagonist. 7,8

3. Ketamine may have local anaesthetic like effect when used intrathecally.9,10,11

This study was undertaken to study the effects of adding preservative-free Ketamine to Bupivacaine Hydrochloride $0.5 \%$ (Heavy) for spinal anaesthesia in lower limb and lower abdominal surgeries. 


\section{Aim of Study}

The study was aimed to compare the anaesthetic properties of $3 \mathrm{~mL} 0.5 \%$ hyperbaric bupivacaine and $2.5 \mathrm{~mL} 0.5 \%$ hyperbaric bupivacaine combined with $0.5 \mathrm{~mL}(25 \mathrm{mg})$ of preservative-free ketamine given intrathecally.

The following parameters were observed in this study of spinal Bupivacaine with and without Ketamine.

Onset of sensory blockade up to $\mathrm{T}_{10}$ level, intraoperative and postoperative vital signs, duration of analgesia and side effect.

\section{MATERIALS AND METHODS}

The ethical committee approval was taken and a prospective observational study was done in 60 ASA I and II patients posted for elective lower limb and lower abdominal surgeries in the Dept. of Anaesthesiology, Govt. T. D. Medical College, Alappuzha.

\section{Inclusion Criteria}

- $\quad$ ASA I and II patients.

- $\quad$ Age group 20 to 50 years.

- Weight 50 to $70 \mathrm{~kg}$.

- $\quad$ Elective surgery.

\section{Exclusion Criteria}

- Not willing for spinal anaesthesia.

- Coagulopathies.

- $\quad$ CNS and CVS disorders.

- Allergy to Bupivacaine/Ketamine.

\section{Pre-0p Evaluation}

A thorough pre-anaesthetic check-up was done. Detailed history, systemic examination, relevant and routine investigations were carried out. Procedure was explained to the patient and an informed consent was obtained. Patients posted for lower limb and lower abdominal surgeries are occasionally given bupivacaine alone or in combination with ketamine in our department; 60 patients were included in two groups of 30 each.

Patients who received $2.5 \mathrm{~mL}$ of $0.5 \%$ Bupivacaine (Heavy) $+0.5 \mathrm{~mL}$ of preservative-free Ketamine $(25 \mathrm{mg}$ ) were observed and selected as Group 1 and patients who received $3 \mathrm{~mL}$ of $0.5 \%$ Bupivacaine (Heavy) were observed and selected as Group 2.

All patients were kept fasting for 8 hours prior to surgery. Pre-medicated with T. Ranitidine $150 \mathrm{mg}$ : T. Metoclopramide $10 \mathrm{mg}$, T. Alprazolam $0.25 \mathrm{mg}$ HS on pre-op day and 6 A.M. on day of surgery. Baseline pulse rate and Blood pressure were recorded. Intravenous access was established and patients were pre-loaded with $20 \mathrm{~mL}$ per kg of crystalloid solution 20 minutes prior to giving subarachnoid block. All patients were given Inj. Midazolam $1.0 \mathrm{mg}$ in the operation theatre before giving subarachnoid block. Preoperative monitors used were pulse oximeter, blood pressure monitor and ECG. Baseline vital signs were recorded. Patients were positioned in the lateral decubitus position. After preparation with povidone iodine, local infiltration with $1 \%$ lignocaine $2 \mathrm{~mL}$ was given in at L3-L4 interspace. Subarachnoid block was administered in L3-L4 space with 25-G Quincke's spinal needle and the proposed drug was injected. Patients were then turned to supine position and oxygen given via facemask at $6 \mathrm{~L} / \mathrm{mt}$. The following parameters were observed.
Subarachnoid block administration time, onset of sensory blockade noted. (The time of drug administration to loss of pinprick sensation at T10 level). This was checked every 30 seconds. Time at which surgery started was noted. Intraoperative vitals- Blood pressure was recorded every 2 minutes for first 30 minutes, then every 5 minutes till the end of surgery. Mean Arterial Pressure (MAP) less than 20\% of baseline was treated with rapid infusion of fluid bolus. If still uncorrected, bolus doses of Inj. Mephentermine $6 \mathrm{mg} \mathrm{I/V}$ were given. The baseline value of MAP and lowest recording were used for statistical analysis. Heart rate was monitored continuously. Bradycardia ( $\leq 60 \mathrm{bpm}$ ) was noted and treated with Injection Atropine $0.6 \mathrm{mg} \mathrm{I} / \mathrm{V}$ if there was associated hypotension. Atropine was also given if the heart rate went below $50 \mathrm{bpm}$.

Time of completion of surgery was noted and duration recorded.

Intraoperative and postoperative complications like nausea, vomiting, shivering, sedation and nystagmus were noted. Patients were shifted to post-op ward and monitored for 24 hours. Nausea and vomiting were treated with Inj. Ondansetron $4 \mathrm{mg} \mathrm{I} / \mathrm{V}$ and shivering was corrected with warm I/V fluids, warm blanket, Inj. Dexamethasone $8 \mathrm{mg} \mathrm{I/V}$. Time of request of rescue analgesic was recorded and duration of analgesia calculated.

\section{Analysis of Data}

In the present study, the data collected were entered into a master chart and statistical tables were prepared. In order to compare the quantitative data, the statistical constants like mean and standard deviation were computed. The equality of the mean value of the two groups were tested by applying Student's ' $t$ ' test. Diagrams and charts were also drawn to give due importance to the most salient findings. All statistical calculations were done by using SPSS software. P value was calculated and interpreted as-

- P Value $<0.05$ statistically 'significant.'

- $\quad$ P Value $>0.05$ statistically 'not significant.'

\section{RESULTS}

\begin{tabular}{|c|c|c|c|c|}
\hline Parameter & Group 1 & Group 2 & T value & P value \\
\hline n & $\mathbf{3 0}$ & $\mathbf{3 0}$ & & 0.928 \\
\hline Weight & $\begin{array}{c}36.97+/- \\
8.23\end{array}$ & $\begin{array}{c}37.17+/- \\
8.84\end{array}$ & 0.09 & $0.33+/-$ \\
4.65 & $\begin{array}{c}61.73+/- \\
4.75\end{array}$ & 0.49 & 0.623 \\
\hline $\begin{array}{c}\text { Duration of } \\
\text { Surgery } \\
\text { (Minutes) }\end{array}$ & $\begin{array}{c}67.3+/- \\
11.6\end{array}$ & $\begin{array}{c}61.7+/- \\
11.7\end{array}$ & 1.92 & 0.059 \\
\hline
\end{tabular}

Table 1. Patient Characteristic and Duration of Surgery

Table 1 shows groups are comparable with respect to age and weight of the patients and duration of surgery.

\begin{tabular}{|c|c|c|c|}
\hline Group & No & Mean & SD \\
\hline Group 1 & 30 & 92.50 & 4.10 \\
\hline Group 2 & 30 & 129.67 & 7.76 \\
\hline \multicolumn{3}{|c|}{ Table 2. Two-Sample 't' Test for Comparison of Onset of } \\
Blockade up to T10 Level \\
\hline
\end{tabular}

There is statistically significant difference in the onset of block between groups. 


\begin{tabular}{|c|c|c|c|c|c|}
\hline Group & & PR $<$ 60 & PR $>$ 60 & $\begin{array}{c}\text { Chi- } \\
\text { Square } \\
\text { Value }\end{array}$ & $\begin{array}{c}\text { P } \\
\text { value }\end{array}$ \\
\hline Group 1 & 30 & 2 & 28 & 4.32 & $<0.05$ \\
\cline { 1 - 4 } Group 2 & 30 & 8 & 22 & & \\
\cline { 1 - 3 } & & &
\end{tabular}

Table 3. Chi-Square Test showing Change in Pulse Rate (PR) among Groups

Above table show statistically significant difference in pulse rate between two groups.

\begin{tabular}{|c|c|c|c|}
\hline Group & & Mean & SD \\
\hline Group 1 & 30 & 14.53 & 1.20 \\
\hline Group 2 & 30 & 23.63 & 1.45 \\
\hline Table 4. Two Sample 't' Test for Percentage Reduction in \\
Mean Arterial Pressure from Baseline \\
\hline
\end{tabular}

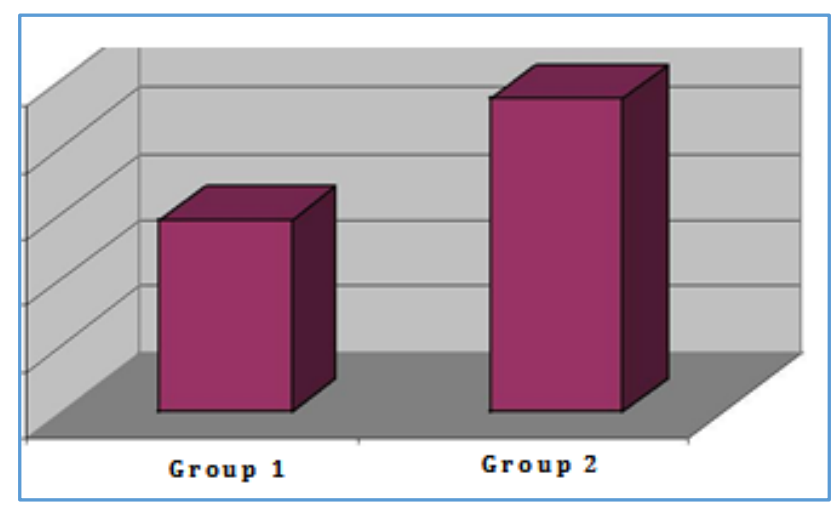

Figure 1. Blood Pressure \% Reduction in MAP from Baseline

Statistical test show significant difference in blood pressure fall and groups differ significantly.

\begin{tabular}{|c|c|c|c|}
\hline Group & & Mean & SD \\
\hline Group 1 & 30 & 199 & 34 \\
\hline Group 2 & 30 & 210.50 & 4.02 \\
\hline \multicolumn{3}{|c|}{ Table 5. Showing Duration of Analgesia between } \\
Group 1 and Group 2 \\
\hline
\end{tabular}

The statistical test shows no significant difference.

Therefore, the two groups are comparable.

\begin{tabular}{|c|c|c|c|c|c|}
\hline Group & \multicolumn{5}{|c|}{ Complications } \\
\hline & Shivering & Sedation & Nystagmus & Nausea & Nil \\
\hline Group 1 & 0 & 10 & 2 & 3 & 15 \\
\hline Group 2 & 10 & 4 & 0 & 0 & 16 \\
\hline \multicolumn{7}{|c|}{ Table 6. Comparison of Occurrence of Complications } \\
\hline
\end{tabular}

\section{DISCUSSION}

Ketamine, a phencyclidine derivative is a potent analgesic/anaesthetic, which has been tried as adjuvant drug with intrathecal local anaesthetics. The advantages of ketamine over the conventional local anaesthetic agents are that it stimulates the cardiovascular and respiratory systems; onset of anaesthesia is faster than local anaesthetics and the sensory block produced is near total. Effects of preservativefree intrathecal ketamine result from NMDA receptor antagonism, opiate receptor agonism and local anaestheticlike action. $4,5,6,7,8,9,10,11$

In our study, 30 patients received $2.5 \mathrm{~mL}$ of Bupivacaine hydrochloride $0.5 \%$ (Heavy) with $0.5 \mathrm{~mL}(25 \mathrm{mg})$ of preservative-free Ketamine hydrochloride and 30 patients received $3 \mathrm{~mL}$ of Bupivacaine hydrochloride 0.5\% (Heavy) alone for spinal anaesthesia.

Both groups were similar in distribution with respect to age, sex, height, weight, ASA grading and duration of surgery as evidenced by statistical analysis. Time of onset of sensory blockade was studied by noting the time from administration of the drug intrathecally to the bilateral loss of pinprick sensation at T10 dermatome. It was found that the onset of sensory block in the Bupivacaine only group was $129.67 \mathrm{sec}$ (Mean), while in the Bupivacaine plus Ketamine group it was $92.5 \mathrm{sec}$ (mean) and this was statistically significant $(\mathrm{P}=0.000)$. These results correlated with the studies done by Dipasri Bhattacharya et al, ${ }^{12} \mathrm{H}$. Unlugenc et al ${ }^{13}$ and $\mathrm{T}$. Togal et al. ${ }^{14}$ Dipasri Bhattacharya et al in the study showed that the onset of sensory blockade is faster in the Ketamine group (1 to 2 minutes) when compared with the Bupivacaine group (2 to 6.5 minutes). T. Togal et al in their study of Ketamine added to Bupivacaine for spinal anaesthesia for prostate surgery showed that intrathecal Ketamine $(0.1 \mathrm{mg} / \mathrm{kg})$ administered with a low-dose Bupivacaine $(7.5 \mathrm{mg})$ provides shorter onset time for sensory block.

The degree of hypotension was compared between the two groups. Fall in mean arterial pressure in the Bupivacaine only group was $23.63 \%$ (mean), while in the Bupivacaine plus Ketamine group was $14.53 \%$ (mean). This was statistically significant $(\mathrm{P}=0.000)$. Hypotension was corrected by infusing boluses of normal saline and intravenous injections of Mephentermine $6 \mathrm{mg}$. A comparatively better haemodynamic profile in the Bupivacaine plus Ketamine group can be attributed to the immediate sympathomimetic effects of Ketamine when injected directly into the central nervous system (Ivankovich AD, Minletich DJ, Reimannc et al ${ }^{15}$ ).

Bradycardia (HR less than $60 \mathrm{bpm}$ ) was observed in 8 out of 30 patients in the Bupivacaine and 2 out of 30 patients in the Bupivacaine plus Ketamine group. This was statistically significant. Bradycardia was managed with intravenous injection of Atropine $0.6 \mathrm{mg}$.

The time of request of rescue analgesia was noted and the duration of analgesia was observed in both the groups. The mean duration of analgesia in Bupivacaine only group was 210.5 minutes, whereas in the Bupivacaine plus Ketamine group it was 199 minutes. $\mathrm{P}$ value is 0.076 . This was statistically insignificant. S. Kathrivel et $\mathrm{al}^{11}$ found that addition of Ketamine to spinal Bupivacaine had local anaesthetic sparing effects. It did not provide extended postoperative analgesia, nor did it decrease the postoperative analgesia requirements. In our study, the duration of analgesia was comparable in both the groups.

Nausea and vomiting was not observed in the Bupivacaine only group, while 3 patients had so in the Bupivacaine plus Ketamine group. This was managed with Inj. Ondansetron $4 \mathrm{mg}$ I/V. S. Kathirvel et al ${ }^{11}$ in his study of effects of intrathecal Ketamine added to Bupivacaine for spinal anaesthesia also noted a higher incidence of nausea and vomiting in the Bupivacaine plus Ketamine group.

Shivering was noted in 10 patients in the Bupivacaine group, while none of the patients in the Bupivacaine plus Ketamine group had so. NMDA receptor antagonists modulate central thermoregulatory control mechanism. Ketamine, which is an NMDA receptor antagonist inhibits 
post-anaesthetic shivering. ${ }^{16}$ Shivering was of Grade 1 to 2 in 7 patients, which was managed with warm intravenous fluids and warm blanket; 3 patients had Grade 3 shivering, which was managed with warm intravenous fluids, warm blanket and Inj. Dexamethasone $8 \mathrm{mg}$ given intravenously.

Sedation was noticed in 4 of the patients in the Bupivacaine only group and 10 of the patients in the Bupivacaine plus Ketamine group. The sedation was mild and the patients were easily arousable from sleep.

Nystagmus was not seen in the Bupivacaine only group, while 2 patients of the Bupivacaine plus Ketamine group had so. The nystagmus noticed could be due to systemic absorption of Ketamine or due to circulation of Ketamine through the CSF. S. Kathirvel et $\mathrm{al}^{11}$ noticed the significant increase in the incidence of nystagmus and sedation in the Ketamine added group.

\section{RESULTS}

It was found that the onset of sensory block in the Bupivacaine only group was $129.67 \mathrm{sec}$ (Mean), while in the Bupivacaine plus Ketamine group it was $92.5 \mathrm{sec}$ (Mean) and this was statistically significant $(\mathrm{P}=0.000)$. Fall in mean arterial pressure in the Bupivacaine only group was $23.63 \%$ (Mean), while in the Bupivacaine plus Ketamine group was $14.53 \%$ (Mean). This was statistically significant $(\mathrm{P}=0.000)$. Incidence of bradycardia was statistically lower in the Bupivacaine plus Ketamine group. There is no statistically significant difference in the duration of analgesia in both the groups. Side effects like nausea, vomiting, sedation and nystagmus were more with the Bupivacaine plus Ketamine group.

Shivering was noted in 10 patients in the Bupivacaine group, while none of the patients in the Bupivacaine plus Ketamine group had so.

\section{Summary}

There is a statistically significant faster onset of action with the Bupivacaine plus Ketamine group. The degree of hypotension and the incidence of bradycardia were statistically lower in the Bupivacaine plus Ketamine group. There is no statistically significant difference in the duration of analgesia in both the groups. Side effects like nausea, vomiting, sedation and nystagmus were more with the Bupivacaine plus Ketamine group. None of the patients in the Bupivacaine plus Ketamine group developed shivering, whereas 10 patients in the Bupivacaine only group had shivering.

\section{CONCLUSION}

Preservative-free ketamine can be added to Bupivacaine $0.5 \%$ (Heavy) for spinal anaesthesia in lower abdominal and lower limb surgeries, which would produce optimal operating conditions with a faster onset of sensory blockade and a better haemodynamic profile. The mild sedation and the local anaesthetic sparing effects can be beneficial.

Further studies can aim at greater reduction in bupivacaine dose with addition of ketamine without compromising the anaesthetic effects.

\section{Limitations of Study}

Sample size was less and was not calculated.

\section{REFERENCES}

[1] Kitahata LM, Taub A, Kosaka Y. Lamina specific suppression of dorsal horn unit activity by ketamine hydrochloride. Anaesthesiology 1973;38:4-11.

[2] Smith DJ, Westfall DP. Ketamine interact with opiate receptor as an agonist. Anaesthesiology 1980;53(3):55.

[3] Pekoe GM, Smith DJ. Neuro chemical basis of ketamine and morphine. Anaesthesiology 1980;53(3):54.

[4] Finck AD, Ngai SH. Opiate receptor mediation of ketamine analgesia. Anaesthesiology 1982;56(4):2917.

[5] Pekoe GM, Smith DJ. The involvement of opiate and monoaminergic neuronal systems in the analgesic effects of ketamine. Pain 1982;12(1):57-73.

[6] Yang CY, Wong CS, Chang JY, et al. Intrathecal ketamine reduces morphine requirements in patients with terminal cancer pain. Canadian Journal of Anaesthesia 1996;43(4):379-83.

[7] Hirota K, Lambert DG. Ketamine: its mechanism of action and unusual clinical uses. British Journal of Anaesthesia 1996;77(4):441-4.

[8] Hong Y, Henry JL. NMDA receptor antagonists block cardiovascular responses to intrathecal administration of D-baclofen in the rat. European journal of pharmacology 1992;216(2):257-63.

[9] Frenkel C, Urban BW. Molecular actions of racemic ketamine on human CNS sodium channels. British journal of Anaesthesia 1992;69:292-7.

[10] Gebhardt B. Pharmacology in clinical results with peridural and intrathecal administration of ketamine. Anaesthesia 1994;43(2):S34-40.

[11] Kathirvel S, Sadhasivam S, Saxena A, et al. Effects of intrathecal ketamine added to bupivacaine for spinal anaesthesia. Anaesthesia 2000;55(9):899-904.

[12] Bhattacharya D, Banerjee A. A comparative study of clinical effects of intrathecal hyperbaric bupivacaine and ketamine in hyperbaric solution. Indian Journal of Anaesthesia 2004;48(2):116-20.

[13] Unlugenc H, Ozalevli M, Gunes Y, et al. A double blind comparison of intrathecal S (+) ketamine and fentanyl combined with bupivacaine $0.5 \%$ for caesarean delivery. European Journal of Anaesthesiology 2006;23(12):1018-24.

[14] Togal T, Demirbilek S, Koroglu A, et al. Effects of S (+) ketamine added to bupivacaine for spinal anaesthesia for prostate surgery in elderly patients. European Journal of Anaesthesiology 2004;21(3):193-7.

[15] Ivankovich AD, Miletich DJ, Charles R, et al. Cardiovascular effects of Centrally administered ketamine in goats. Anaesthesia Analgesia 1974;53:924-33.

[16] De Witte J, Sessler DI. Perioperative shivering: physiology and pharmacology. Anaesthesiology 2002;96(2):467-84. 